\title{
"Migraine side effect" and stroke recurrence in late follow-up after transcatheter patent foramen ovale closure as secondary prevention of cryptogenic thromboembolism
}

\author{
Magdalena Kumor ${ }^{1}$, Elżbieta K. Biernacka1, Marcin Demkow ${ }^{1}$, Marek Konka ${ }^{1}$, Anna E. Płatek², \\ Michalina Jagodzińska², Piotr Hoffman ${ }^{1}$ \\ ${ }^{1}$ Institute of Cardiology, Warsaw, Poland \\ ${ }^{2}$ Warsaw Medical University, Warsaw, Poland
}

Postep Kardiol Inter 2014; 10, 3 (37): 155-160

DOI: $10.5114 /$ pwki.2014.45141

\begin{abstract}
A bstract
Introduction: Patent foramen ovale (PFO) is associated with cryptogenic strokes, recurrent transient neurologic deficits, sleep apnea, decompression illness and migraines with aura.

Aim: We verify cryptogenic embolism recurrence after transcatheter PFO closure in patients younger than 55 years old, and determine the prevalence of migraine with aura before and after PFO closure.

Material and methods: We sent a questionnaire concerning the recurrence of stroke or transient ischemic attack (TIA) and the presence of migraine symptoms before and after PFO closure to 224 consecutive patients (mean age $40.9 \pm 9$ years; 103 men; 108 patients < 40 years old, 116 patients 40-55 years old) after successful PFO transcatheter closure as secondary prevention of cryptogenic embolism.

Results: The mean follow-up period was $37.8 \pm 32.5$ (median 27) months. Stroke or TIA recurred in 6 patients (2.6\%), all of whom were over 40 years old at the time of closure. The median time of recurrence was 24 months. Two patients $(0.89 \%)$ died, but the deaths were not related to the device nor to thromboembolism. Migraine occurred in the study group before closure in 68 (30.4\%) patients. After the procedure 55 (80.9\%) reported improvement or disappearance of migraine symptoms.

Conclusions: Recurrent strokes after PFO closure are rare, and they occur more often in patients over 40 years old at the time of closure. The PFO closure results in migraine subsiding or symptoms noticeably ameliorating.
\end{abstract}

\section{Introduction}

Foramen ovale allows blood shunt from the right to left atrium in foetus circulation. Birth entail formation of fosa ovalis or patent foramen ovale (PFO), a physiological remnant of foramen ovale, is a potential connection between the atria. The PFO present in $20-27 \%$ of the population in autopsy studies but only in $10-15 \%$ of patients in contrast-enhanced transesophageal echocardiography (TEE), which seems to be a normal variant [1].

The PFO is associated with cryptogenic strokes, recurrent transient neurologic deficits, sleep apnoea, decompression illness, and migraines with aura [2].

The PFO and migraine are linked because the prevalence and severity of migraine symptoms decreases after PFO closure due to other causes [3]. The migraine symptoms ameliorate also after PFO closure in uncontrolled studies [4].

Migraine with aura implies a new potential indication to PFO closure. A few theories (PFO theory among them) relate stroke and migraine [5]. The PFO demonstrates twice the prevalent in patients with migraine, and migraine is twice as common in PFO patients than in controls $[4,6]$. Population studies [7-11] and three meta analyses [5, 12-14] reveal that migraine roughly doubles the risk for ischaemic stroke: the higher the incidence of migraine attacks, the grater increase in risk $[15,16]$. Despite the doubled relative risk in migraine sufferers for ischaemic stroke, in absolute terms stroke remains a rare event in people with migraine, particularly in young individuals [5].

The hard evidence that closure exceeds pharmacological strategy in secondary prevention of stroke or migraine treatment is lacking because of short follow-ups in randomised studies, randomisation bias (the large number of off-label closures), and difficulties with indication assignment for the closing strategy [17]. Conflicting data have come from several randomised versus numerous observational trails $[18,19]$.

Corresponding author:

Magdalena Kumor MD, PhD, Department of Adult Congenital Heart Disease, Institute of Cardiology, 42 Alpejska St, 04-628 Warsaw, Poland, phone: +48 2234344 57, e-mail: magdakumor@wp.pl

Received: 17.04.2014, accepted: 18.07.2014. 
Nevertheless, in our centre we prefer the closing strategy. We follow-up a significant number of patients after the PFO transcatheter procedure. We conducted the study to show long-term safety of the closing strategy, especially because rare but severe late adverse events after PFO or atrial septal defect (ASD) closure have been reported [20, 21].

\section{Aim}

We verify cryptogenic embolism recurrence after transcatheter PFO closure in patients younger than 55 years old, and determine the prevalence of migraine with aura before and after PFO closure.

\section{Material and methods}

The study group consisted of 224 consecutive patients (mean age $40.9 \pm 9$ years) who underwent transcatheter PFO closure between 1999 and 2011 as secondary prevention of cryptogenic thromboembolism. Most of the patients who had their PFO closed were after stroke, one suffered from peripheral embolism of a subclavian artery,

Table I. Study group characteristics

\begin{tabular}{|c|c|}
\hline Data, variables & No. of patients \\
\hline \multicolumn{2}{|l|}{ Indication to closure: } \\
\hline One stroke & 178 \\
\hline Multiple strokes & 3 \\
\hline TIA & 41 \\
\hline Peripheral embolism & 1 \\
\hline Decompression illness & 1 \\
\hline \multicolumn{2}{|l|}{ Age [years]: } \\
\hline$<40$ & 108 \\
\hline $40-55$ & 116 \\
\hline \multicolumn{2}{|l|}{ Gender: } \\
\hline Male & 103 \\
\hline Female & 121 \\
\hline \multicolumn{2}{|l|}{ Stroke potential risk factors: } \\
\hline Smokers & 49 \\
\hline Overweight BMI 25-30 kg/m² & 61 \\
\hline Obese $\mathrm{BMI}>30 \mathrm{~kg} / \mathrm{m}^{2}$ & 15 \\
\hline Cholesterol LDL level $>3 \mathrm{mmol} / \mathrm{l}$ & 67 \\
\hline Hypertension > 140/90 mm Hg & 68 \\
\hline Diabetes & 1 \\
\hline \multicolumn{2}{|l|}{ Device type: } \\
\hline Amplatzer & 218 \\
\hline CARDIA & 6 \\
\hline Lost to follow-up & 33 \\
\hline
\end{tabular}

Table II. Treatment options after procedure

\begin{tabular}{ll} 
Years & \multicolumn{1}{c}{ Treatment } \\
\hline $1999-2003$ & At least 6 months aspirin (ASA) \\
\hline $2004-2006$ & At least 6 months ASA + clopidogrel \\
\hline $2007-2011$ & 3-6 months ASA + clopidogrel
\end{tabular}

and one had multiple events of decompression illness. Stroke risk factors presented in about one third of the group (Table I). Patients with at least 3-month follow-up were included in the study. All patients had transthoracic echocardiography performed the day after closure and 3 months after the procedure, and most patients were followed at month 12 after closure in outpatient settings and underwent electrocardiography (ECG) and transthoracic echocardiography (TTE).

We sent a questionnaire concerning the recurrence of stroke or TIA and the presence and intensity of migraine symptoms before and after PFO closure. We asked questions about diagnosis with migraine with aura, which were set by a neurologist. Patients suspected of stroke or TIA were invited to undergo additional tests in an outpatient department (clinical evaluation, TTE, ECG obligatory and TEE, neurological examination if indicated).

Every patient received antithrombotic treatment after the procedure (Table II). There were 33 (14.7\%) patients lost for the follow-up.

\section{Results}

The mean follow-up period was $37.8 \pm 32.5$ (median: 27) months (range: $3-151$ months).

Stroke or TIA recurred in 6 patients (2.6\%) (stroke 5 patients, TIA - 1 patient), all of whom older than 40 years at the time of closure. The median time of recurrence was 24 months (range: 7-46 months), and it was significantly more prevalent in older patients (41-55 years) than in younger ones (< 40 years) $(2.6 \%$ vs. $0 \%$, log rank, Mantel-Cox, $p<0.02$ ) (Figures 1, 2).

Only 1 patient, who suffered from cryptogenic stroke two years after the procedure and was 49 years old at the time of closure, was a migraine sufferer. Residual shunt as the cause of stroke was excluded.

Two patients (0.89\%) died. One of them (39 years old at the time of closure) died in an accident 5 years after closure and the other (47 years old) had a myocardial infarction 6 years after closure (Figure 1).

Migraine with aura occurred in the study group before PFO closure in 68 (30.4\%) patients: 19 (27.9\%) men

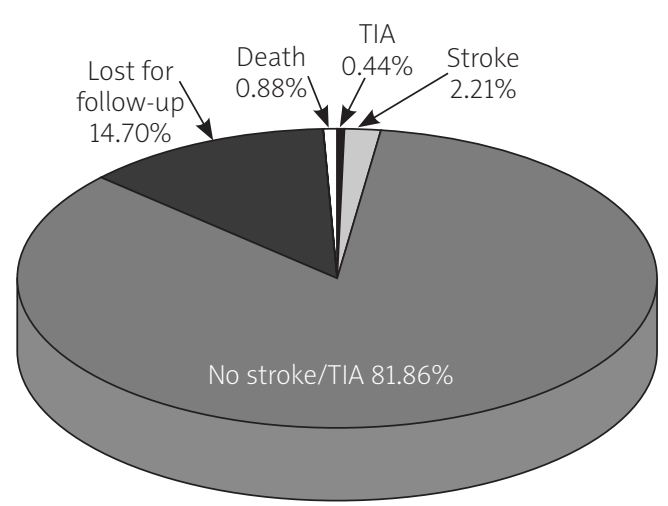

Figure 1. Recurrences of stroke and TIAs 
and 49 (72\%) women. The mean age in the subgroup was $40.3 \pm 8.9$ years. The mean follow up in the subgroup was $38.6 \pm 31.7$ months (range: 3-151 months, median: 28 months).

After the procedure 55 patients $(80.8 \%)$ reported a noticeable improvement (expressed as lower incidence or severity of migraine attacks, in patients' subjective opinion) or disappearance of migraine symptoms. There were 13 patients (19.1\%) without improvement. The difference was statistically significant $(p<0.0001)$.

\section{Discussion}

Cryptogenic stroke represents up to $40 \%$ of all ischaemic strokes [22]. Thorough investigation of the established causes of stroke settles diagnosis of exclusion.

Paradoxical embolisation seems the most likely mechanism of cryptogenic stroke through the PFO, but studies suggest other possible hypotheses such as the formation and release of thrombus from within the PFO tunnel or the passage of vasoactive humoral substances (that are normally degraded in pulmonary circulation) [23]. Retrospective, case-controlled studies have shown a higher prevalence of PFO in patients with cryptogenic stroke [24].

The extent of PFO-related stroke risk in the population still remains controversial [25]. A cause-effect relationship between PFO and cryptogenic stroke has not been convincingly demonstrated. Furthermore, several studies have consistently found that the presence of a PFO does not inherently increase the risk of recurrent stroke [22, 26-30]. This may be due to relatively low overall rate of stroke recurrence in patients with cryptogenic stroke and PFO (ranging in studies from $0 \%$ to $12 \%$ per year, with an average annualised risk across studies of approximately $2 \%)[28,29]$.

In a recently published study, with a mean follow-up period of 15 years (in 86 patients, less than 75 years old at the time of enrolment), the recurrent risk for stroke was rather high: $15 \%$ after a mean period of 4.9 years, reflecting a calculated event rate of $0.98 \%$ per year in this cohort [31]. The occurrence of stroke was not associated with differences in baseline data, the presence of atrial septal aneurysm, PFO size, or chosen treatment (PFO closure, anticoagulation, antithrombotic therapy). Most patients in this study were treated medically (only three underwent intervention therapy) [31]. In another study of 280 patients, with a mean follow-up of 2.6 years, the recurrence rate was $0.6 \%$ per year for patients treated with interventional closure devices and $13 \%$ per year for medical treatment with acetylsalicylic acid [32]. In a long-term follow up (mean $34 \pm 23$ months) of 405 patients after HELEX septal occluder the annual stroke rate was 1.2\% [33].

In our study stroke recurrence was rare, was observed in patients older than 40 years at the time of closure, and

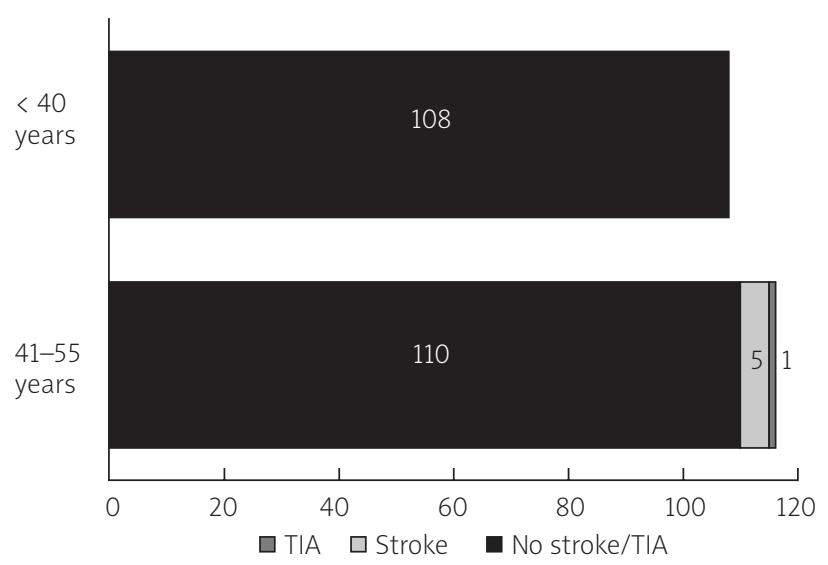

Figure 2. Recurrences of stroke and TIA in younger and older patients

had no association with the residual shunt or device-related abnormality.

A meta-analysis of observational, non-randomised trials gave conflicting results for a randomised (CLOSURE I) trial $[34,35]$. In the observational studies, the incidence rate of recurrent stroke was 0.36 (95\% confidence interval (CI): 0.24-0.56) events per 100 person-years with closure versus 2.53 (95\% Cl: 1.91-3.35) events per 100 personyears with medical therapy. The incidence rate for the closure arm in the CLOSURE I trial was almost four times higher (1.34; 95\% Cl: 0.69-2.34) and did not differ from the medical treatment.

The observational studies (incorporated 10 times more patients) favour closing PFO in secondary prevention of cryptogenic stroke. Randomised studies (CLOSURE I, RESPECT, and PC-trial) failed to show superiority of any particular closing strategy [18, 19, 34]. Reasons for failure may be as follows: I) a lower event rate than previously reported in the medical arm (lower baseline risk in the CLOSURE I trial); II) higher event rates in the closure arm that reflect unrealistic estimates in observational studies (the authors are less keen to publish unfavourable results); III) the lack of selection of high-risk patients with PFO-related events in randomised trials; and IV) too short (2 years) follow-up not fully capturing the benefit of the intervention. High-risk patients with clinical indicators of paradoxical embolism (large shunt, associated atrial septal aneurysm, Valsalva manoeuvre at stroke onset, evidence of deep vein thrombosis, evidence of a hypercoagulable state, stroke recurrence despite antithrombotic treatment, multiple clinical cerebrovascular events or multiple ischaemic lesions on brain magnetic resonance imaging (MRI), and absence of any conventional stroke risk factors) were probably more often treated with closure off-protocol and were not included in randomised trials [36-38].

We do not recognise the long-term risk after PFO closure. Since reports of rare but severe adverse events, such as device erosion, researchers have postulated the 
formation of a registry and a focus on long-term safety of ASD or PFO device closure [21].

Observational studies report low periprocedural risk. Severe early complications like tamponade, embolisation with device, milder transient supraventricular arrhythmia, or atrial fibrillation present rarely [34, 39-41]. But in the MIST randomised trial, periprocedural complications were reported in up to $11 \%$ of patients, which seems high in relatively healthy patients with migraine.

The prevalence and causes of surgical explantation of PFO closure devices evaluated in a multicentre survey (more than 13,000 closures performed in 9 years) showed only 38 devices $(0.28 \%, 95 \% \mathrm{Cl}: 0.20-0.37 \%)$ removed surgically. Chest pain, often determined secondary to nickel allergy, was revealed as most common cause. Other causes included persistence of a residual shunt, the presence of thrombus on the device, pericardial effusion, perforation of the atrium or aortic root, recurrent strokes, and the development of endocarditis. The removal prevalence seems device-dependent; the rate of explantation was 1 in 126 for CardioSEAL devices, 1 in 480 for Amplatzer devices, and 1 in 600 for Helex devices [20].

No patient in our study required device removal during follow-up.

The closing strategy increases the risk for infective endocarditis 6 months after procedure as well as bleeding risk during aspirin or double antiplatelet or warfarin therapy at least 3 months after the procedure. In our group we did not observe infective endocarditis or bleeding.

The migraine and stroke link in literature exists only in younger patients $[14,16,42]$ and it associates more in women than in men, because migraine is more common in women. In our study, migraine proved three times more prevalent in patients with cryptogenic stroke or TIA than in the general population (30\% vs. $10 \%$ ). The gender distribution in the study agreed with population data. The theories, but not evidence, of a link between stroke and migraine are based on the following: the hypothesis of the occurrence of a migrainous infarction (the decrease in blood flow related to the aura reaches the ischaemic level or leads to dissection), the hypothesis of treatment (used to acutely abort migraine attacks, particularly vasoconstrictors increasing the risk for stroke), the hypothesis of risk factors (an increased prevalence of vascular risk factors in patients with migraine), the hypothesis of cortical spreading depression (the low threshold for cortical spreading depression that characterises the brain in migraine also lowers the threshold for cerebral ischaemia) [5].

The first PFO and migraine link was shown when an improvement in the prevalence and severity of symptoms was seen after PFO closure from other causes [3]. Similarly to cryptogenic stroke, hard evidence is lacking to show that the closing PFO strategy can contribute to healing migraines. Several causes make it difficult to show the efficacy of the new treatment. Migraine is known for its spontaneous variability and response rate to preventive medications in about $50 \%$ of cases as well as in around $20-30 \%$ for placebo (in well conducted contemporary clinical trials). Most observations that closing PFO cures migraine were in patients after stroke, an event that may alter the course of migraine per se. Also, medications used in some studies after PFO closure, e.g. aspirin $[43,44]$ and clopidogrel, exert little influence on migraine. Nonetheless, our results support data that show migraine symptoms are reduced in at least $75 \%$ of patients after PFO closure due to different causes [45]. In the literature, this positive effect was more pronounced in migraine sufferers with aura, and was observed regardless of residual shunt [45-47].

In one small group of patients after stroke, the decrease in migraine prevalence was due to stroke and was enhanced by device closure [48].

We could not distinguish whether the amelioration of symptoms was the result of closure or part of the natural course of migraine after stroke.

Unfortunately, the randomised MIST trail failed to show any significant difference between the medical and the closure strategy in migraine treatment. The problem needs more studies to be carried out [49].

The study is retrospective and non-randomized. We included only successful closures of PFO in secondary prevention of thromboembolism to follow up. We lack almost $15 \%$ of patients follow-up data. The data about current pharmacological treatments are limited. Also some neurological data about type of stroke lacks. Patients were referred from different neurological hospitals, and not all neurological data were available.

\section{Conclusions}

Recurrent strokes after percutaneous PFO closure with septal occluder are rare and probably not related with PFO, they occur more often in patients older than 40 years at the time of closure. The PFO closure seems effective in secondary prevention of cryptogenic stroke, in patients younger than 40 years, but is less beneficial in older patients. Migraines are seen more often in patients with PFO than in the general population, and their gender prevalence is consistent with the population. Percutaneous PFO closure with a septal occluder results in migraines subsiding or symptoms noticeably ameliorating in a significant percentage of patients.

\section{References}

1. Hagen PT, Scholz DG, Edwards WD. Incidence and size of patent foramen ovale during the first 10 decades of life: an autopsy study of 965 normal hearts. Mayo Clin Proc 1984; 59: 17-20.

2. Johansson MC, Eriksson P, Dellborg M. The significance of patent foramen ovale: a current review of associated conditions and treatment. Int J Cardiol 2009; 134: 17-24. 
3. Wilmshurst PT, Nightingale S, Walsh KP, Morrison WL. Effect on migraine of closure of cardiac right-to-left shunts to prevent recurrence of decompression illness or stroke or for haemodynamic reasons. Lancet 2000; 356: 1648-51.

4. Schwedt TJ, Demaerschalk BM, Dodick DW. Patent foramen ovale and migraine: a quantitative systematic review. Cephalalgia 2008; 28: 531-40.

5. Kurth T, Chabriat H, Bousser MG. Migraine and stroke: a complex association with clinical implications. Lancet Neurol 2012; 11: $92-100$.

6. Bousser MG. Patent foramen ovale and migraine: evidence for a link? Headache Currents 2006; 3: 44-51.

7. Tzourio C, Iglesias S, Hubert JB, et al. Migraine and risk of ischaemic stroke: a case-control study. BMJ 1993; 307: 289-92.

8. Kurth T, Slomke MA, Kase CS, et al. Migraine, headache, and the risk of stroke in women: a prospective study. Neurology 2005; 64: 1020-6.

9. Stang PE, Carson AP, Rose KM, et al. Headache, cerebrovascular symptoms, and stroke: the Atherosclerosis Risk in Communities Study. Neurology 2005; 64: 1573-7.

10. Henrich JB, Horwitz RI. A controlled study of ischemic stroke risk in migraine patients. J Clin Epidemiol 1989; 42: 773-80.

11. MacClellan LR, Giles WH, Cole J, et al. Probable migraine with visual aura and risk of ischemic stroke: The Stroke Prevention in Young Women Study. Stroke 2007; 38: 2438-45.

12. Etminan M, Takkouche B, Isorna FC, Samii A. Risk of ischaemic stroke in people with migraine: systematic review and metaanalysis of observational studies. BMJ 2005; 330: 63.

13. Schurks M, Rist PM, Bigal ME, et al. Migraine and cardiovascular disease: systematic review and meta-analysis. BMJ 2009; 339: b3914.

14. Spector JT, Kahn SR, Jones MR, et al. Migraine headache and ischemic stroke risk: an updated meta-analysis. Am J Med 2010; 123: 612-24.

15. Donaghy M, Chang CL, Poulter N. Duration, frequency, recency, and type of migraine and the risk of ischaemic stroke in women of childbearing age. J Neurol Neurosurg Psychiatry 2002; 73: 747-50.

16. Kurth T, Schurks M, Logroscino G, Buring JE. Migraine frequency and risk of cardiovascular disease in women. Neurology 2009; 73: 581-8.

17. Kumor M. Patent foramen ovale: to close or not to close - still the question. Postep Kardiol Inter 2012; 8: 42-7.

18. Meier B. PC Trial update: late-breaking trial preview. TCT 2012; October 25, 2012; Miami, FL.

19. Carroll JD. RESPECT: Late-breaking trial preview. TCT 2012; October 25, 2012; Miami, FL

20. Verma SK, Tobis JM. Explantation of patent foramen ovale closure devices: a multicenter survey. JACC Cardiovasc Interv 2011; 4: 579-85.

21. FDA Miller R. FDA panel recommends new studies of ASD occluders. theheart.org. [Clinical Conditions > Interventional/ Surgery > Interventional/Surgery]; May 26, 2012. Accessed at http://www.theheart.org/article/1406543.do on May 31, 2012).

22. Sacco RL, Ellenberg JH, Mohr JP, et al. Infarcts of undetermined cause: the NINCDS Stroke Data Bank. Ann Neurol 1989; 25: 382-90.

23. Halperin JL, Fuster V. Patent foramen ovale and recurrent stroke: another paradoxical twist. Circulation 2002; 105: 2580-2.

24. Overell JR, Bone I, Lees KR. Interatrial septal abnormalities and stroke: a meta-analysis of case control studies. Neurology 2000; 55: 1172-9.
25. Messè SR, Kasner SE. Patent foramen ovale in cryptogenic stroke: not to close. Circulation 2008; 118: 1999-2004.

26. De Castro S, Cartoni D, Fiorelli MMR, et al. Morphological and functional characteristics of patent foramen ovale and their embolic implications. Stroke 2000; 31: 2407-13.

27. Bogousslavsky J, Garazi S, Jeanrenaud X, et al. Stroke recurrence in patients with patent foramen ovale: the Lausanne Study. Lausanne Stroke with Paradoxal Embolism study Group. Neurology 1996; 46: 1301-5.

28. Mas JL, Arquizan C, Lamy C, et al. Patent Foramen Ovale and Atrial Septal Aneurysm Study Group. Recurrent cerebrovascular events associated with patent foramen ovale, atrial septal aneurysm, or both. N Engl J Med 2001; 345: 1740-6.

29. Almekhlafi MA, Wilton SB, Rabi DM, et al. Recurrent cerebral ischemia in medically treated patent foramen ovale: a metaanalysis. Neurology 2009; 73: 89-97.

30. Messe SR, Silverman IE, Kizer JR, et al. Practice parameter: recurrent stroke with patent foramen ovale and atrial septal aneurysm: report of the Quality Standards Subcommittee of the American Academy of Neurology. Neurology 2004; 62: 1042-50.

31. Fischer D, Gardiwal A, Haentjes J, et al. Susteined risk of recurrent thromboembolic events in patients with patent foramen ovale and paradoxical embolism: long-term follow-up over more than 15 years. Clin Res Cardiol 2012; 101: 297-303.

32. Schuchlenz HW, Weihs W, Berghold A, et al. Secondary prevention after cryptogenic cerebrovascular events in patients with patent foramen ovale. Int J Cardiol 2005; 101: 77-82.

33. Heinisch C, Bertog S, Wunderlich N, et al. Percutaneous closure of the patent foramen ovale using the HELEX® Septal Occluder: acute and long-term results in 405 patients. Eurolntervention 2012; 8: 717-23.

34. Kitsios GD, Dahabreh IJ, Abu Dabrh AM, et al. Patent foramen ovale closure and medical treatments for secondary stroke prevention: a systematic review of observational and randomized evidence. Stroke 2012; 43: 422-31.

35. NMT Medical Announces Preliminary Results of CLOSURE I PFO/ Stroke Trial Company Release - 06/17/2010.

36. Alsheikh-Ali AA, Thaler DE, Kent DM. Patent foramen ovale in cryptogenic stroke incidental or pathogenic? Stroke 2009; 40: 2349-55.

37. Kent DM, Thaler DE. Is patent foramen ovale a modifiable risk factor for stroke reccurence? Stroke 2010; 41 (Suppl. 10): S26-30.

38. Giacomo G, Abbas M, Corea F. Prevention strategies for cardioembolic stroke: present and future perspectives. Open Neurol J 2010; 4: 56-63.

39. Demkow M, Ruzyłło W, Kepka C, et al. Transcatheter closure of patent foramen ovale in patients with cryptogenic stroke. Kardiol Pol 2004; 61: 101-9.

40. Kumor M, Baranowski R, Jakubowska E, et al. Evaluation of cardiac arrythmias and conduction abnormalities one year after transcatheter closure of atrial septal defect and patent foramen ovale. Folia Cardiol 2002; 9: 553-8.

41. Khairy P, O'Donnell C, Landzberg M. Transcatheter closure versus medical therapy of patent foramen ovale and presumed paradoxical thromboemboli: a systematic review. Ann Intern Med 2003; 139: 753-60.

42. Wahl A, Praz F, Tai T, et al. Improvement of migraine headaches after percutaneous closure of patent foramen ovale for secondary prevention of paradoxical embolism. Heart 2010; 96: 967-73.

43. Peto R, Gray R, Collins R, et al. Randomized trial of prophylactic daily aspirin in British male doctors. Br Med J 1988; 296: 313-6. 
44. Diener H, Hartung E, Chrubasik J, et al.; Study Group. A comparative study of oral acetysalicyclic acid and metoprolol for prophylactic treatment of migraine. A randomized, controlled, double-blind, parallel group phase III study. Cephalagia 2001; 21: $120-8$.

45. Jesurum J, Fuller C, Kim C, et al. Frequency of migraine headache relief following patent foramen ovale "closure" despite residual right-to-left shunt. Am J Cardiol 2008; 102: 916-20.

46. Wilmshurst P, Nightingale S, Walsh K, Morrison WL. Clopidogrel reduces migraine with aura after transcatheter closure of persistent foramen ovale and atrial septal defects. Heart 2005; 91 : 1173-5.

47. Azarbal B, Tobis J, Suh W, et al. Association of interatrial shunts and migraine headaches: impact of transcatheter closure. J Am Coll Cardiol 2005; 45: 489-92.

48. Lapergue B, Rosso C, Hadrane L, et al. Frequency of migraine attacks following stroke starts to decrease before PFO closure. Neurology 2006; 67: 1099-100.

49. Dowson A, Mullen MJ, Peatfield R, et al. Migraine Intervention With STARFlex Technology (MIST) trial: a prospective, multicenter, double-blind, sham-controlled trial to evaluate the effectiveness of patent foramen ovale closurewith STARFlex septal repair implant to resolve refractory migraine headache. Circulation 2008; 117: 1397-404. 